\title{
DESAIN KERANGKA BLOCKCHAIN TERHADAP PENDIDIKAN: A SURVEY
}

\section{Edward Guustaaf ${ }^{1}$, Untung Rahardja ${ }^{2}$, Qurotul Aini ${ }^{3}$, Nesti Anggraini Santoso ${ }^{4}$, Nuke Puji Lestari Santoso $^{5}$}

${ }^{1}$ Vexanium, ${ }^{2345}$ Universitas Raharja

Jl. Jenderal Sudirman No.40, RT.002 / RW.006, Cikokol, Kota Tangerang, Indonesia

Iedward@vexanium.com, ${ }^{2}$ untung@raharja.info, ${ }^{3}$ aini@raharja.info, ${ }^{4}$ nesti@raharja.info, ${ }^{5}$ nuke@raharja.info.

Abstrak-Blockchain adalah buku besar yang secara bersamaan terdesentralisasi dan terdistribusikan. Terdapat Node yang berfungsi untuk mencatat semua histori transaksi di Blockchain dengan semua jaringan yang berbeda. Blockchain memiliki sifat kekal atau tidak dapat diubah, sehingga kemungkinan terjadi kecurangan dalam teknologi Blockchain sangat kecil. Hal ini tentu menjadi teknologi yang sangat praktis dan aman bagi dunia pendidikan dalam melakukan sertifikasi digital, pencatatan, dan lain sebagainya. Dengan adanya teknologi Blockchain diharapkan dapat menyelesaikan masalah yang sering terjadi di dunia pendidikan. Desain pendidikan berbasis Blockchain memiliki harapan besar dalam menurunkan tingkat kecurangan yang selalu terjadi di dunia pendidikan. Penelitian ini dilakukan dengan menggunakan metode komprehensif, di mana kami akan fokus mendalami desain pendidikan berbasis Blockchain, fitur-fitur Blockchain yang digunakan, dan layanan pendidikan berbasis Blockchain sebagai hasil dari penelitian ini. Ketiga bagian tersebut sangat berperan penting dalam meningkatkan implementasi teknologi Blockchain di dunia pendidikan.

Kata Kunci-Blockchain, Pendidikan, Sertifikat Digital, Teknologi

Abstract-Blockchain Blockchain is a ledger that is simultaneously decentralized and distributed. There is a Node that functions to record all transaction history on the Blockchain with all different networks. Blockchain has an immutable or immutable nature, so the possibility of fraud in Blockchain technology is very small. This is certainly a very practical and safe technology for the world of education in conducting digital certification, recording, and so on. With Blockchain technology, it is hoped that it can solve problems that often occur in the world of education. The blockchain-based educational design has great hopes in reducing the level of cheating that always occurs in the world of education. This research was conducted using a comprehensive method, where we will focus on exploring Blockchain-based education design, Blockchain features used, and Blockchain-based educational services as a result of this research. Each of these sections plays an important role in improving the implementation of Blockchain technology in the world of education.

Keywords- Blockchain, Education, Digital Certificate, Technology

\section{PENDAHULUAN}

Bitcoin Crypto Currency merupakan Teknologi Blockchain yang pertama kali dikembangkan. Sejak ide itu diciptakan pada tahun 2008 telah menarik perhatian, sehingga menjadi daya tarik dalam Blockchain [1]. Teknologi Blockchain ini merupakan teknologi yang dapat mengatur dirinya sendiri dan terdesentralisasi [2], serta membuat catatan terbuka yang telah dieksekusi dari peristiwa terkomputerisasi atau semua transaksi dan akan dibagikan kepada pihak yang ikut serta. Untuk menunjukkan keaslian setiap transaksi pada Blockchain, maka akan diverifikasi dengan tanda tangan digital. Informasi yang disimpan pada Blockchain akan disegel dan tidak dapat diubah, karena penggunaan tanda tangan digital dan enkripsi [3].
Teknologi Inovatif ini digunakan dalam beberapa aplikasi seperti pendidikan, industri bisnis, perawatan kesehatan dan tata kelola, karena semua transaksi yang diimplementasikan dalam Blockchain sifatnya transparansi, tidak berubah, dan keamanan [4], [5], [6]. Dalam menjalankan teknologi ini dibutuhkan keamanan, sehingga pengguna tidak khawatir dengan privasi data yang mereka berikan [7]. Orang dapat melihat masa depan dari teknologi Blockchain di era saat ini sebagai teknologi yang berkembang, karena meningkatnya minat teknologi informasi dan komunikasi secara global, hal ini menyebabkan perubahan di segala bidang termasuk bidang pendidikan [8], [9]. Pada minat teknologi, teknologi Blockchain dirasa memiliki efek yang positif [10]. 
Pada era sekarang pula, Blockchain membakar isu mengenai pendidikan lalu memberi solusi yang tepat untuk mereka serta menyoroti isu utama. Sertifikat merupakan metode konvensional menampilkan nilai di atas kertas yang dianggap menggambarkan gambar dari diri seseorang. Mencetak sertifikat digital merupakan pemberian tren terbaru dari teknologi Blockchain saat ini [11]. Adanya kemungkinan sertifikat kertas, ada sertifikat digital sudah dapat memproses manajemennya secara sederhana [12]. Teknologi Blockchain menyediakan mekanisme yang adil dengan sifat transparansi lengkap untuk mendanai desain pendidikan dan hibahnya, serta menjadi penyebab kurangnya kecurangan tingkat lanjut yang terjadi [13] Keamanan dari Blockchain juga dapat digunakan dalam proses manajemen suatu jurnal karya ilmiah sebagai pendukung keamanan dari manajemen jurnal itu sendiri [14], dapat digunakan pula pada keaslian suatu ijazah [15].Berbagai desain kerangka Blockchain dalam dunia pendidikan diperkenalkan untuk keuntungan yang akan didapatkan pengguna, hal ini dilakukan untuk perubahan sistem pendidikan saat ini. Tren pendidikan terbaru dapat digambarkan melalui celah yang ada. Tren pendidikan terbaru memberikan pandangan terhadap kesenjangan antara rantai blok dan implementasinya.

Hal ini juga mengamati fitur-fitur blockchain yang ditawarkan dan sedang digunakan oleh desain kerangka Blockchain dalam pendidikan yang ada untuk meningkatkan implementasi pada teknologi Blockchain dalam pendidikan dengan menggunakan fitur-fitur Blockchain. Beberapa desainnya yaitu, Sony Global Education, Origin-Stamp, Edgecoin, GradeBase dan TeachMePlease, desain ini terus bertambah banyak setiap waktu. Masalah Skalabilitas menjadi satu dari beberapa masalah yang ada [2], [4]. Skalabilitas yang dimaksud diartikan sebagai waktu yang diambil untuk mencapai konsensus dan menaruh transaksi di dalam blok. Dalam penelitian ini terdapat beberapa bagian pembahasan yang terlampir pada Gbr. 1.

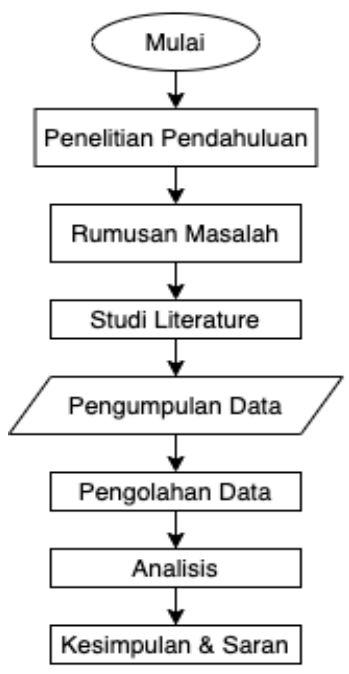

Gbr 1. Flowchart Penelitian

\section{TINJAUAN LITERATUR}

\section{A. Blockchain}

Catatan data yang telah menjadi bagian Blockchain serta telah dihosting di jaringan didesentralisasi maka tidak dapat diubah, ini merupakan arti Blockchain secara sederhana. Blockchain adalah peer to peer, dimana data atau catatan yang telah didistribusikan akan aman di dalam kriptografi [16]. Semua catatan hampir tidak mungkin dapat memperbarui atau bahkan merusak catatan pada seluruh objek jaringan. Karena Semua catatan yang ada ditangani oleh sekelompok Node yang tidak memungkinkan dimiliki oleh satu entitas. Semua transaksi yang akan dibawa oleh blok saling terikat lalu, agar dapat diverifikasi dan ditandatangani dengan cara menggunakan bukti kriptografi yang telah dipecahkan oleh Blockchain dan relawannya [17].

\section{B. Jenis-jenis Blockchain}

Terdapat tiga jenis dasar dari Blockchain, yaitu:

1. Blockchain yang diizinkan merupakan Blockchain yang tidak dapat mengeluarkan transaksi yang mereka lakukan sendiri ataupun melihat catatannya serta bergabung dengan suatu komunitas secara bebas, merupakan tindakan Blockchain yang diizinkan dan akan bertindak sebagai ekosistem tertutup.

2. Blockchain yang tidak diizinkan merupakan Blockchain yang sifatnya tidak umum atau terbuka untuk siapa semua orang yang ingin mengaksesnya.

3. Hybrid Blockchain merupakan Blockchain ini menggunakan gabungan antara dua Blockchain, yaitu Blockchain publik, dan blockchain pribadi. Pada jaringan ini data data Blockchain yang tidak diizinkan tetap dapat diakses dari tempat Blockchain dengan menggunakan hak akses tertentu yang disimpan. Jenis Blockchain ini tidak terbuka untuk semua orang, namun Blockchain ini menyediakan fitur dasar secara diam-diam seperti keterlancaran, integrasi dan keamanan.

\section{Fitur Blockchain}

Beberapa fitur dasar Blockchain, yaitu:

1. Desentralisasi: Kontrol pada Blockchain tidak terletak pada kekuasaan pemerintah, namun terdesentralisasi. Desentralisasi ini merujuk pada prosedur penyimpanan, pelestarian, konfirmasi data dan transmisi, yang terjadi di dalam Blockchainnya bergantung pada struktur kerangka kerja terdistribusi [18], [19].

2. Mekanisme Konsensus: Mekanisme konsensus digunakan di dalam Blockchain dengan tujuan mencapai kesepakatan pada data tunggal pada keadaan dimana jaringan berada diantara kerangka kerja multi-agen atau proses yang didistribusikan. Mekanisme ini sangat membantu dalam proses 
pencatatan. Terdapat beberapa prosedur dalam mekanisme ini yaitu DPOS, POW, dan POS [4], [20].

3. Mata uang: Pada era revolusioner saat ini, dari semua usulan cryptocurrency yang ada, bitcoin merupakan mata uang digital pertama di dunia. Bitcoin Teknologi Blockchain yang merupakan virtual atau mata uang digital, dimana teknologi ini memastikan transaksi end-to-end yang membuat transaksi ini terlindungi dan dapat dipercaya, hal ini merupakan bagian dari properti cryptocurrency. Dalam pembentukan mata uang ini digunakan Algoritma pembangunan yang berbeda. Oleh karena itu, Produk gabungan dari cryptocurrency dengan Blockchain dapat digunakan di beberapa aspek, contohnya aspek keuangan dan akuntansi [4], [21].

4. Kontrak Pintar: Merupakan protokol Blockchain yang dibutuhkan agar memungkinkan pengembang untuk dapat membuat kode perjanjian keuangan pada Blockchain, yang nantinya akan diaktifkan oleh semua pihak yang terlibat [4], [21], [22]. Kontrak ini memastikan kualitas dan keamanan transaksi secara signifikan, tidak hanya mengurangi biaya luar yang ada di dalam transaksi konvensional. Kontrak Pintar ini dibangun untuk mengamankan transaksi yang terjadi di dalam Blockchain, pada pertengahan tahun 1990 protokol ini dikembangkan pertama kali oleh Nick Zabo [23].

5. Kekekalan: Jika data telah dimasukkan, maka data tersebut tidak dapat diubah lagi [24]. Data yang ada juga tidak mungkin untuk dimanipulasi, karena dikendalikan oleh semua orang yang berkaitan. Jika ingin melakukan perusakan (membuat perubahan agar tidak sah) maka perlu mengubah catatan yang telah disimpan di dalam sistem sebanyak lebih dari 51 persen [4], [21].

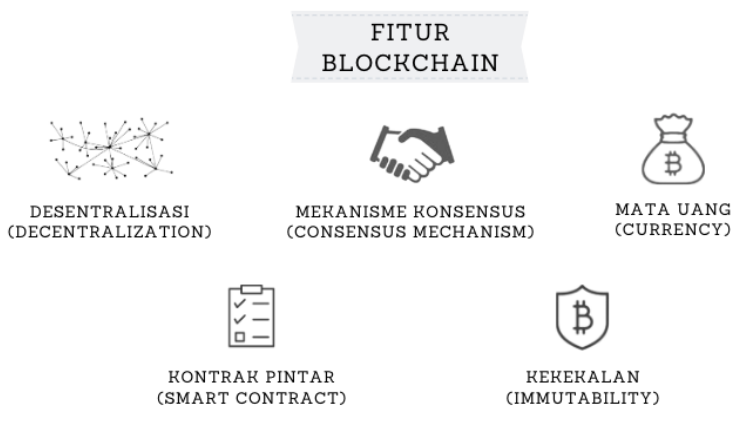

Gbr 2. Fitur Blockchain

\section{Aplikasi Blockchain dalam Pendidikan}

Blockchain merupakan teknologi yang mempunyai aplikasi dalam dunia pembelajaran baik di tingkat kelembagaan, kelompok, individu, nasional bahkan sampai tingkat internasional. Di mana ini berlaku untuk semua jenis kerangka referensi seperti Sekolah dasar sampai sekolah menengah atas, universitas, perguruan tinggi, bidang kerja sama, beasiswa, dan pengetahuan. Dengan kepercayaan bermigrasi ke arah teknologi dan bukannya pada institusi, teknologi menjadi target utamanya dibandingkan struktur hierarkis lama. Jika sebelumnya fitur desain kerangka Blockchain hanya Sony Global Education, Origin-Stamp, Edgecoin, GradeBase dan TeachMePlease, seiring berjalanya waktu desain kerangka Blockchain mengalami perkembangan. Berikut ini merupakan beberapa desain pendidikan yang digunakan di seluruh dunia dengan berbasis Blockchain :

APPII berguna untuk memastikan latar belakang akademik dan kualifikasi guru dan siswa, dengan menggabungkan kontrak pintar dan Blockchain. Aplikasi ini diharapkan dapat memaksimalkan kemampuan setiap orang. Para pengguna dapat membuat profil mereka lalu CV akademik seperti riwayat pendidikan dan transkrip [25].

Sony Global Education (SGE) merupakan platform yang melindungi dan juga berbagi catatan siswanya menggunakan basis Blockchain. Sony Global Education dan Sony Corporation mengumumkan bahwa mereka akan membentuk sistem pada 10 Agustus 2017, dimana secara khusus teknologi Blockchain akan diterapkan dalam sistem pendidikan [26], [27], [28], [29].

Parchment adalah forum yang digunakan untuk memproses program, menilai kualifikasi akademik dan juga menghasilkan sertifikat. Mahasiswa dapat mendiskusikan kinerja akademik dengan calon pemberi kerja dengan mudah [30]. Ini adalah layanan kredensial elektronik yang paling diterima secara luas yang memungkinkan banyak pihak seperti institusi akademik, siswa, dan juga pemberi kerja untuk mendaftar, lalu memverifikasi dan juga membagikan kredensial dengan mudah di dalam lingkungan yang aman.

Edgecoin untuk memastikan pengaturannya hebat, edgecoin memiliki strategi dalam menyusun Daap, yang bertujuan menurunkan efisiensi, penipuan yang dilindungi, dan juga biaya. Edgecoin ini mempercepat sistem dan menyimpan dokumen akademik seperti gelar. Edgecoin merupakan langkah reformasi yang inovatif dalam perdagangan pendidikan, karena dapat mengurangi gangguan dari pendidikan yang tidak lancar dan juga tidak sehat, dengan memvalidasi prosedur dan sertifikasinya. Jadi mereka dapat bertahan dari segala bentuk kerusakan, penipuan dan kerugian dalam bentuk apapun [21].

GradBase merupakan sistem yang didasarkan pada teknologi Bitcoin Blockchain untuk verifikasi catatan pendidikan. GradBase menyediakan sistem profil yang sederhana tampilannya dan murah. Sistem ini memiliki kode QR yang akan dimasukkan ke dalam CV siswa. Dengan dukungan LinkedIn pada perluasan browser web bertujuan untuk meningkatkan pengalaman pengguna.

$O D E M$ adalah platform yang memungkinkan siswa, guru, dan pihak terkait untuk terhubung dalam layanan dan kursus yang relevan. Selain itu dalam memperoleh pendidikan yang baik, ODEM memiliki peluang dalam 
tantangan yang dihadapi oleh siswa. karena menggunakan framework yang didukung oleh Blockchain dapat meningkatkan kemajuan pendidikan, biaya rendah, dan mudah ditangani [30].

Origin-Stamp merupakan stamping waktu yang Page|239 aman, yang memiliki tujuan untuk memastikan keamanan pada data digital. Hal ini dapat dilakukan dengan menentukan sidik jari ekonomi yang datanya berasal dari klien, dan menjaga agar sidik jari tersebut dapat disimpan kedalam teknologi Blockchain bitcoin secara permanen [29].

Blockcerts Merupakan platform yang dikembangkan oleh MIT Lab yang berkolaborasi dengan sistem pendidikan untuk catatan pendidikan. Blockcerst digunakan untuk memverifikasi dokumen yang bersifat resmi dan menerbitkannya [31]. Didalamnya juga terdapat aplikasi dompet yang dipakai untuk mengenkripsi informasi siswa. Dengan tujuan utamanya untuk menghasilkan e-sertifikat yang valid serta aman dengan menggunakan teknologi bitcoin Blockchain [32], [33].

Echolink mengurus hubungan entitas pendidikan seperti guru, siswa, dan organisasi yang ada merupakan tujuan dari sistem berbasis Blockchain ini. Sistem ini menyimpan data yang telah terverifikasi dari individu, yang memiliki keterkaitan dengan karir profesional dalam format hash dan data tersebut tidak dapat diubah pada Blockchain yang tidak memiliki izin. Semua informasi yang ada di dalam sistem ini diberikan oleh sumber yang terpercaya. Proyek yang telah diidentifikasi lebih lanjut akan dibandingkan dan sintetis yang terkait akan disajikan pada bagian ini [33], [31].

TeachMePlease (TMP) Menyediakan database berupa lembaga pembelajaran baik untuk sekolah secara online maupun secara offline, Program yang tersedia sangat berbeda daripada kelas belajar kelompok bagi anak-anak mulai dari sesi individu sampai instruktur pribadi. Program ini perlu bekerja secara lembut pada data, seperti tugas, solusi, kursus, dan penilaian. Dibandingkan Blockchain TMP ini memerlukan izin yang lebih sedikit, seperti EOS atau Ethereum akan memerlukan pengungkapan data kepada publik. Walaupun bisa masuk akal, seperti Hyperledger, juga memerlukan status yang terbuka yang tidak perlu dipertanyakan [32], [33].

TABEL I.

APLIKASI BLOCKCHAIN DENGAN FITUR BLOCKCHAIN

\begin{tabular}{|c|l|l|l|l|l|l|l|}
\hline $\begin{array}{c}\text { Projects / } \\
\text { Feature }\end{array}$ & Content & Store & $\begin{array}{c}\text { E- } \\
\text { Certficate }\end{array}$ & Scoring & $\begin{array}{c}\text { Coope } \\
\text { rative }\end{array}$ & Job & $\begin{array}{c}\text { Provi } \\
\text { ding }\end{array}$ \\
\hline APPII & & & & & & & \\
\hline SGE & & & & & & & \\
\hline Parchment & & & & & & & \\
\hline ODEM & & & & & & & \\
\hline GradeBase & & & & & & & \\
\hline Edge coin & & & & & & & \\
\hline $\begin{array}{c}\text { Origin } \\
\text { Stamp }\end{array}$ & & & & & & & \\
\hline Blockcerts & & & & & & & \\
\hline
\end{tabular}

\begin{tabular}{|c|l|l|l|l|l|l|l|} 
EchoLink & & & & & & & \\
\hline TMP & & & & & & & \\
\hline ODEM & & & & & & \\
\hline
\end{tabular}

\section{METODE PENELITIAN}

Metode yang digunakan yaitu komprehensif di mana berfokus pada identifikasi, pengumpulan, dan interpretasi dari semua penelitian yang tersedia yang bertujuan menjawab permasalahan yang ada secara lengkap, detail dan menyeluruh. Pedoman yang disediakan oleh "Barbara Kitchenham" akan menjadi pedoman yang kami ikuti dalam melakukan penelitian ini. Hasil dari pemeriksaan ini membantu kami dalam membedakan antara kesenjangan penelitian yang dipikirkan dengan area penelitian yang terkait dengan teknologi Blockchain. SLR terdiri atas 3 tahap utama menurut Kitchenham yaitu:

- Merencanakan peninjauan.

- Melakukan peninjauan.

- Melaporkan ulasan.

Dalam menyelesaikan penelitian ini, Kami akan mengikuti tahap-tahap di atas. Gambar 2 Menunjukkan tahap-tahap yang setelahnya akan dibagi menjadi beberapa tahap lagi.
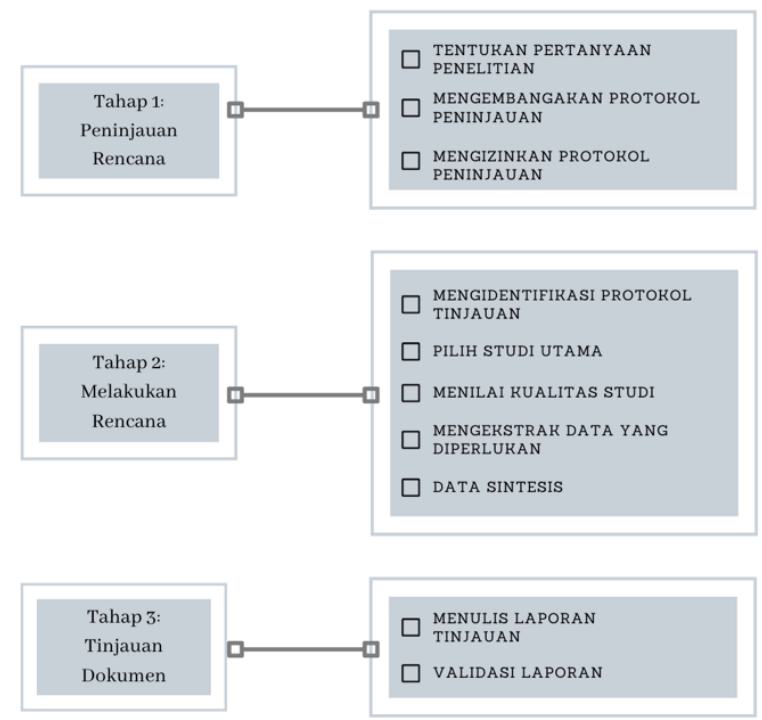

Gbr 3. Metodologi SLR

\section{A. Kebutuhan Melakukan SLR}

Berdasarkan klasifikasi studi ini, disahkan bahwa terdapat beberapa lubang yang belum dibicarakan dan harus diisi agar mendapat saran lebih lanjut, hal itu diketahui setelah melakukan analisis terhadap studi ini. Selama proses saat melakukan penelitian ini, hanya ditemukan beberapa studi yang membahas desain kerangka Blockchain di dunia pendidikan. Namun hal itu tidak dilakukan dengan suara penuh dalam kertas waktu tunggal. Selanjutnya, hal ini mengarahkan kami untuk melakukan penelitian secara kuantitatif dan tepat agar kami dapat mencapai tujuan. 


\section{B. Pertanyaan penelitian}

Mengemukakan pertanyaan penelitian, merupakan bagian bagian pertama penelitian

RQ1: Apa saja desain kerangka Blockchain dalam dunia pendidikan?

Page | 240 RQ2: Layanan apa saja yang digunakan dalam desain kerangka Blockchain dalam dunia pendidikan?

RQ3: Teknologi apa saja yang digunakan dalam desain kerangka Blockchain dalam dunia pendidikan?

\section{Strategi Pencarian}

Dalam bidang pendidikan Blockchain melakukan peran yang penting. Melalui Google Scholar, kami mempelajari makalah analisis yang berbeda. Kami cenderung mencari kata kunci seperti "Blockchain", dan 'edukasi' di Google Scholar. Pada subjek tersebut ditemukan 200 makalah. Setelah mempelajari makalah tersebut, kami memilih beberapa makalah yang benarbenar terkait dengan kata kunci yang kami gunakan. Lalu memeriksa bermacam-macam makalah penelitian, setelah itu melaporkan sebuah artikel yang telah diterbitkan di berbagai konferensi dan jurnal.

\section{Kriteria Inklusi dan Pengecualian}

Terdapat 35 makalah yang telah dikumpulkan, yang berkaitan dengan kata kunci serta pertanyaan penelitian untuk dimasukkan. Kami memilih 14 studi utama perihal desain kerangka Blockchain dalam dunia pendidikan yang sesuai dan kami gunakan sebagai tinjauan literatur. Makalah lain dihilangkan karena tidak memiliki keterkaitan dengan topik "Desain Kerangka Blockchain terhadap pendidikan: A Survey", karena makalah itu membahas "Teknologi Blockchain dalam Pendidikan".

TABEL II.

PAPER DENGAN ID REFERENSI

\begin{tabular}{|c|c|c|}
\hline ID & $\begin{array}{c}\text { Tahun } \\
\text { Terbitan }\end{array}$ & Nama Paper \\
\hline [11] & 2021 & $\begin{array}{c}\text { Aplikasi Blockchain dalam Dunia } \\
\text { Pendidikan dengan Metode Systematics } \\
\text { Review }\end{array}$ \\
\hline [15] & 2021 & $\begin{array}{c}\text { Pengaruh } \\
\text { Teknologi Blockchain Terhadap Tingkat } \\
\text { Keaslian Ijazah }\end{array}$ \\
\hline [19] & 2021 & $\begin{array}{c}\text { Manajemen Kontrol Akses Berbasis } \\
\text { Blockchain untuk Pendidikan Online } \\
\text { Terdesentralisasi }\end{array}$ \\
\hline [10] & 2020 & $\begin{array}{c}\text { The Role Of Blockchain As A Security } \\
\text { Support For Student Profiles In } \\
\text { Technology Education System }\end{array}$ \\
\hline [33] & 2018 & $\begin{array}{r}\text { CredenceLedger: A Permissioned } \\
\text { blockchain for Verifiable Academic } \\
\text { Credentials }\end{array}$ \\
\hline [34] & 2017 & $\begin{array}{c}\text { Stampery Blockchain Timestamping } \\
\text { Architecture (BTA)-Version 6 }\end{array}$ \\
\hline
\end{tabular}

\begin{tabular}{|c|c|c|}
\hline [21] & 2018 & $\begin{array}{c}\text { Exploring blockchain technology and its } \\
\text { potential applications for education }\end{array}$ \\
\hline$[8]$ & 2020 & $\begin{array}{r}\text { Blockchain Technology intro } \\
\text { Gamification on Education }\end{array}$ \\
\hline$[35]$ & 2020 & $\begin{array}{c}\text { Embedding a Blockchain Technology } \\
\text { Pattern Into the QR Code for an } \\
\text { Authentication Certificate }\end{array}$ \\
\hline$[36]$ & 2018 & $\begin{array}{r}\text { Blockchain for education: lifelong } \\
\text { lencing passport }\end{array}$ \\
\hline$[32]$ & 2018 & Disciplina: Blockchain for Education \\
\hline$[9]$ & 2019 & $\begin{array}{c}\text { Pemanfaatan Teknologi Blockchain } \\
\text { pada Program Sertifikasi Dosen }\end{array}$ \\
\hline$[37]$ & 2019 & $\begin{array}{c}\text { Design Framework on Tertiary } \\
\text { Education System in Indonesia Using } \\
\text { Blockchain Technology }\end{array}$ \\
\hline$[38]$ & 2018 & $\begin{array}{r}\text { Blockchain Based Professional } \\
\text { Networking and Recruiting Platform }\end{array}$ \\
\hline
\end{tabular}

\section{HASIL}

Pada bagian hasil, terdapat 3 bagian yang telah dibagi. Bagian pertama, melakukan pengelompokan atau klasifikasi beberapa desain kerangka Blockchain yang memiliki keterkaitan dengan pendidikan. Bagian kedua, memfokuskan kepada pelayanan yang tidak biasa dan pelayanan umum dari desain kerangka Blockchain di dunia pendidikan yang telah diidentifikasi. Bagian ketiga, memberi penjelasan mengenai teknologi yang digunakan dalam desain kerangka Blockchain di dunia pendidikan.

\section{A. RQ1: Apa saja desain kerangka Blockchain dalam dunia pendidikan?}

Teknologi telah menghasilkan beberapa metode dan model pendidikan yang baru, hal ini terjadi karena terjadi revolusi yang sangat cepat dalam teknologi [39]. Dalam dunia pendidikan, Teknologi Blockchain sudah membawa perubahan (Revolusi). Pertanyaan penelitian pertama kami berkaitan tentang desain kerangka Blockchain yang dipilih dengan mempelajari makalah ulasan yang ada.

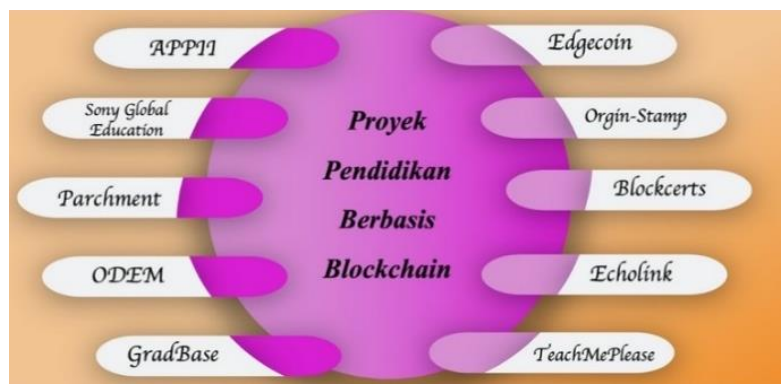

Gbr 4. Proyek Pendidikan berbasis Blockchain

Desain kerangka Blockchain dalam dunia pendidikan yang ada saat ini adalah APII, Sony Global Education Parchment, ODEM, GradeBase, Edgecoin, Origin-Stamp, Blockcerts, Echolink, dan TeachMePlease. Melalui pengantar umum, hal itu 
membuat kami tertarik dalam mencari tahu alasan dibalik terjadinya evolusi ini. Kontribusi kami yaitu :

-Kenapa kita memerlukan desain kerangka pendidikan yang berbasis Blockchain?

Page | 241

Alasannya yaitu karena individu, universitas dan pengusaha saat ini tengah menghadapi banyak sekali tantangan yang berkaitan dengan verifikasi pendidikan, penipuan, membandingkan derajat yang sama di berbagai lembaga pendidikan yang berbeda dan masalah menerjemahkan [40]. Selain itu, adapun mengenai autentifikasi, mencetak, menyimpan sertifikasi serta gelar membutuhkan biaya yang tinggi untuk sekolah dan universitas di berbagai penjuru dunia, Sementara itu e-learning menjadi semakin populer, validasi keterampilan, dan verifikasi sertifikasi tetap ada, karena semua lembaga, perusahaan, dan negara tidak memiliki standar pedoman tertentu agar dapat diterima oleh perusahaan. Setiap individu membutuhkan sesuatu yang dapat membuat mereka lebih mudah dalam melamar pekerjaan serta para perusahaan yang dapat mempekerjakan orang-orang yang telah memenuhi persyaratan.

Hal itu dapat terjadi apabila Industri pendidikan yang bernilai miliaran dolar menemukan solusi agar mereka lebih mudah dalam melakukan verifikasi, validasi dan mengagregasi "catatan pembelajaran" individu. Oleh karena itu kami membutuhkan solusi agar dapat menyelesaikan setiap tantangan yang ada. Jadi, desain pendidikan berbasis Blockchain ini menjadi solusi untuk menyelesaikan tantang itu, karena Blockchain sangat cepat, aman, dan juga efisien biaya dalam menyusun data dan catatan seperti sertifikat elearning, gelar perguruan tinggi, dan lainnya.

\section{B. RQ2 : Layanan apa saja yang ditawarkan dalam desain kerangka Blockchain dalam dunia pendidikan?}

Untuk mengidentifikasi layanan yang ditawarkan oleh desain kerangka Blockchain dalam dunia pendidikan menjadi tujuan utama dari pertanyaan penelitian ini. Hal pertama yang kami lakukan yaitu, mempelajari secara serius mengenai proyek penelitian yang diberikan. Kami mencari tahu mengenai hasil yang diberikan pada gambar 3 setelah melakukan analisis secara mendalam.

Banyak sekali manfaat yang ada di dalam Desain kerangka Blockchain dalam dunia pendidikan yang paling utama yaitu pendekatan desentralisasi yang dapat memecahkan banyak masalah mengenai, pengurangan dokumen, masalah pekerjaan dan keamanan. Untuk memproses beberapa miliar transaksi yang terjadi antara perangkat secara fundamental di adoposilah Blockchain standar yang berguna untuk mengurangi biaya yang memiliki kaitan dengan pemeliharaan pusat data besar yang berpusat dan menyesuaikan dengan kebutuhan kapasitas dan perhitungan yang melebihi miliaran perangkat. Ini akan mencegah dan menghindari satupun kode jaringan dari keruntuhan semua sistem. Tujuan lain desain kerangka Blockchain ini yaitu untuk terus mendukung sistem IoT yang berskala kecil dan menghubungkan para siswa dan guru dalam periode beberapa tahun terakhir, bagaimanapun, hal itu tidak mampu untuk menyediakan kebutuhan yang digunakan untuk memperluas sistem Blockchain dalam pendidikan di masa yang akan datang.

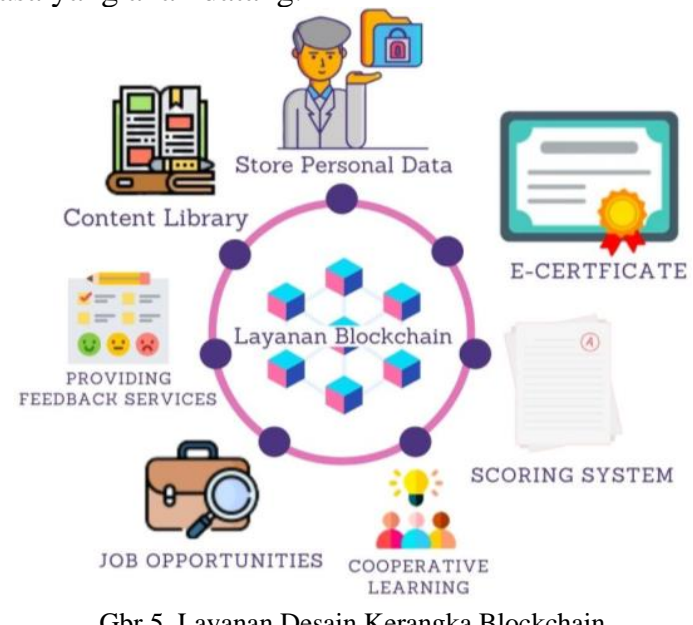

- Content Library: Catatan besar yang menawarkan desain pendidikan berbasis Blockchain dengan menggunakan fitur Blockchain fitur Blockchain desentralisasi dan tingkat transaksi. Dalam layanan ini apabila pelanggan meninggalkan konten pada satu titik di suatu perangkat, maka di perangkat lain ia akan terus mempelajarinya, hal ini karena layanan ini merupakan platform-independent.

- Store Personal Data: Pelanggan bisa menyimpan data pribadi mereka dengan 2 cara yaitu dengan metode Enkripsi dan Anonim. Metode Enkripsi yaitu semua transaksi yang disimpan ke dalam jaringan menampilkan semua orang tetapi dalam bentuk enkripsi. Data adalah enkripsi dengan menggunakan kode yang berbeda-beda, dan semua menyediakan keamanan data yang sama seperti ini. Metode Anonim, teknik ini hanya digunakan untuk Sony Global Education, Transaksi yang tidak diketahui disimpan secara rapat-rapat, tidak ada yang bisa melihat atau mengetahui transaksi tersebut selain pelanggan itu sendiri.

- E-Certificate: Sertifikat resmi dengan menggunakan laju transaksi fitur blockchain akan kita terima karena diberikan oleh Blockchain yang ada. E-Sertifikat merupakan sertifikat digital yang mengambil tanda tangan digital, dengan cara client dapat mencapainya dengan menggunakan kunci pribadi dan kunci publik. Saat ini E-certificate berbasis teknologi tentang dikembangkan guna meminimalisir kecurangan berupa pemalsuan sertifikat. Dengan verifikasi dan autentifikasi [35], 
keamanan sertifikat lebih terjaga ditambah dengan adanya kode hash di dalam sertifikat tersebut [11].

- Scoring System: Dengan menggunakan fitur Blockchain yaitu Smart Contact nilai akan diberikan sesuai dengan prestasi yang didapat oleh siswa. Hanya TeachMePlease dan Sony Global yang memberi layanan sistem penilaian. Jika pada saat proses evaluasi prestasi yang dihasilkan siswa memenuhi syarat maka dinyatakan luar biasa.

- Cooperative Learning: Orang-orang belajar bersama di tempat yang sama pula. Mereka menciptakan pemikiran baru dan membicarakan hal-hal mengenai desain pendidikan berbasis rantai blok, hal tersebut dapat menggunakan fitur-fitur Blockchain desentralisasi dan fitur kontrak pintar.

- Job opportunities: Desain pendidikan berbasis rantai blok ini dapat memberikan peluang pekerjaan kepada seseorang. Mereka memberikan peluang kerja ini kepada orang yang terampil dan juga bersertifikat. Dengan begitu, dengan menggunakan kontrak pintar Blockchain dapat mengurangi pengangguran.

- Providing Feedback Services merupakan desain pendidikan berbasis Blockchain yaitu Tutellus memberikan fasilitas kepada orang untuk memberikan umpan balik, dengan cara menggunakan fitur penelusuran.

TABEL III.

LAYANAN BLOCKCHAIN

\begin{tabular}{|c|c|c|c|c|c|c|c|}
\hline $\begin{array}{c}\text { Projects / } \\
\text { Feature }\end{array}$ & $\begin{array}{c}\text { Conte } \\
\text { nt }\end{array}$ & $\begin{array}{c}\text { Stor } \\
\text { e }\end{array}$ & $\begin{array}{c}\text { Certfica } \\
\text { te }\end{array}$ & $\begin{array}{c}\text { Scorin } \\
\text { g }\end{array}$ & $\begin{array}{c}\text { Cooperati } \\
\text { ve }\end{array}$ & $\begin{array}{c}\text { Jo } \\
\text { b }\end{array}$ & $\begin{array}{c}\text { Providi } \\
\text { ng }\end{array}$ \\
\hline APPII & & & & & & & \\
\hline SGE & & & & & & & \\
\hline $\begin{array}{c}\text { Parchme } \\
\text { nt }\end{array}$ & & & & & & & \\
\hline ODEM & & & & & & & \\
\hline $\begin{array}{c}\text { GradeBa } \\
\text { se }\end{array}$ & & & & & & & \\
\hline $\begin{array}{c}\text { Edge } \\
\text { coin }\end{array}$ & & & & & & & \\
\hline $\begin{array}{c}\text { Origin } \\
\text { Stamp }\end{array}$ & & & & & & & \\
\hline $\begin{array}{c}\text { Blockcert } \\
\text { s }\end{array}$ & & & & & & \\
\hline $\begin{array}{c}\text { EchoLin } \\
\mathbf{k}\end{array}$ & & & & & & & \\
\hline TMP & & & & & & & \\
\hline ODEM & & & & & & \\
\hline
\end{tabular}

C. RQ3: Teknologi apa saja yang digunakan dalam desain kerangka Blockchain dalam dunia pendidikan?

Dengan mengikuti teknologi Blockchain semua desain pendidikan yang telah dibangun memiliki tujuan utamanya yaitu memeriksa semua masalah dan rintangan yang datang sebagai penghalangnya dan mempromosikan rasa pendidikan yang sesungguhnya, hal ini dapat memberikan jalan keluar yang rasional dan menjadi solusi untuk semua masalah yang ada. Masalah utama yang timbul mengenai hal pendidikan yaitu: terlalu banyak dokumen yang sifatnya tradisional, kurangnya keamanan atau perlindungan terhadap data pendidikan, cara menyimpan data yang masih belum memadai, proses dalam sertifikasi tidak efisien dan memakan waktu yang lama, serta penyimpanan catatan yang lama dan tidak dapat diubah, dal lainnya [41]. Oleh karena itu dengan adanya Teknologi Blockchain dalam pendidikan akan memberi kemudahan dalam melakukan verifikasi dan validasi yang awalnya prosesnya sangat lama dan membosankan itu menjadi cepat agar bisa menghemat waktu dan uang yang berharga [37]. Kemiskinan merupakan akar dan penyebab umum dari buta huruf di negara-negara dunia ketiga. Pencapaian yang paling signifikan dari model yaitu mereka memberi kesempatan untuk memperbaiki atau meningkatkan posisi ekonomi dan memberikan pengetahuan keterampilan kepada peserta didik.

TABEL IV

DESAIN KERANGKA BLOCKCHAIN DALAM DUNIA PENDIDIKAN DAN TEKNOLOGI YANG DIGUNAKAn

\begin{tabular}{|c|c|c|}
\hline No & Model & Teknologi \\
\hline 1 & Edgecoin & Proof of Stake (PoS) \\
\hline 2 & Sonny Global Education & Hyperledger \\
\hline 3 & TeachMePlease & DPoS \\
\hline 4 & Blockcerts & POW \\
\hline 5 & GradeBase & POW \\
\hline 6 & Echolink & PoS \\
\hline
\end{tabular}

Edge-Coin menyimpan dokumen pendidikan di bloknya seperti sertifikasi kursus dan gelar, lalu pihak ketiga akan langsung mengkonfirmasi validitasnya. Hal ini dapat mengurangi biaya yang dikeluarkan untuk siswa karena mereka sudah tidak perlu membayar untuk notaris. Hal ini juga dapat mengurangi biaya yang dikeluarkan untuk lembaga karena menghilangkan dokumen yang dibahas pada bagian 2 dan birokrasi.

POS Echolink dan Edge-Coin telah menggunakan sesuatu yang bertentangan dengan Proof of Work yaitu Proof of Stake (PoS). POS merupakan salah satu node yang terpilih untuk sebagian besar Node yang belum terpilih oleh jaringan pada usia tertentu dan kuantitas mereka. Untuk mengawasi situs dipilih beberapa individu tertentu, agar Edge-Coin dan Echolink dapat menangani platformnya lebih cepat, transmisi kontrak pintar berjalan lebih cepat [42].

POW Desain pendidikan berbasis Blockchain yang menggunakan Proof of Work (POW) adalah Gradbase, Origin-Stamp dan Blockcerts. Tujuan dari protokol ini yaitu memvalidasi transaksi. Dengan menggunakan protokol ini, para penambang bersaing antara satu sama lain, untuk menyelesaikan transaksi dengan memecahkan teka-teki kriptografi dan mendapatkan serta mengumpulkan hadiah yang diterima setelahnya 
yang membutuhkan waktu lebih banyak saat pemrosesan.

DPoS Desain pendidikan berbasis Blockchain yang menggunakan protokol DPoS adalah TeachMePlease (TMP). Delegated Proof of Stake (DPoS) memiliki pengertian yaitu algoritma mekanisme konsensus yang menjaga kesepakatan yang tidak dapat dibantah mengenai mengotorisasi transaksi, kenyataan di seluruh jaringan, dan menyediakan platform demokratis digital. Karena kinerjanya dan reputasi yang luar biasa Lisk telah memilihnya sebagai protokol yang dipilih. Bukti yang didelegasikan dari suatu kepemilikan yaitu dengan menggunakan pemungutan suara secara real-time, untuk mencapai konsensus akan dikombinasikan dengan skema nama. Hal itu terlihat dari perbandingan antara protokol konsensus yang memiliki jumlah terkecil dibanding dengan semua konsensus yang ada karena itu paling kooperatif dari semua yang ada. Apa yang terjadi pada jaringan ada dipengaruhi oleh setiap pemegang token.

Lapisan Pribadi dan Publik merupakan bagian dari Arsitektur Blockchain. TeachMePlease. Lapisan Pribadi: Digunakan untuk menyimpan materi-materi yang dilindungi oleh hak cipta dan data yang bersifat pribadi [32]. Lapisan Publik: Digunakan untuk menyediakan akses ke data yang memverifikasi kendala penyimpanan data oleh jaringan dan integritas data pribadi [32].

BOLT Untuk membuat perkembangan yang bersifat pribadi dan profesional yang tersedia untuk banyak orang, yang menjadi sumber keberhasilan dalam membangun dan mensukseskan perusahaan Blockchain, SuccessLife. SuccessLife menggunakan protokol teknologi BOLT. Teknologi ini dapat memungkinkan Provenance dan menciptakan entri di Blockchain.

- Dalam Blockchain tingkat telah ditangkap riwayat pencari pengguna dan ketertarikan pada level. Pada proses ini dapat memberikan pemahaman dan pengetahuan yang lebih baik lagi tentang minat siswa.

- Pelatih dapat mengidentifikasi berapa kali pelajarnya diminta untuk demo dibantu dengan pembuatan entri di tingkat pelajaran Blockchain yang dapat dilihat dari langkah demo.

Hyperledger Platform bisnis serba guna yang mendukung berbagai lembaga pendidikan dalam menyimpan sertifikat digital dan catatan pendidikan adalah Sony Global Helpledger. Memberikan Application Programming Interface (API) menjadi solusi yang bertujuan untuk mengontrol hak pengguna untuk lembaga pendidikan dan menyesuaikan atribut pengumpulan data dan catatan siswa [5], [28].

Dengan memisahkan proses transaksi PoW standar yang sedang dilakukan menjadi tiga fase dapat memecahkan masalah dengan menggunakan Sony hyperledger. Tiga fase itu yaitu: Memesan blok, membangun blok dan memvalidasi masing-masing blok yang ada.

Sharding Merupakan jenis pertisi database yang memisahkan basis data dari yang lebih besar menjadi bagian yang lebih kecil, lebih mudah dikelola, dan lebih cepat yang disebut pecahan data [22]. Sering terjadi, data shard relatif lebih mudah. Akan banyak transaksi yang akan divalidasi secara bersamaan dengan menggunakan cara ini di jaringan Ethereum. Sharding ini memungkinkan perusahaan untuk mendelegasi tugasnya yang berbeda, sehubung dengan adanya Tutellus, sehingga mereka dapat memaksimalkan kapasitas untuk fungsi pendidikannya [43]

Dengan total lebih dari 100 pengguna telah membuktikan bahwa Tutellus menjadi sangat populer di dunia berbahasa Spanyol. Tutellus juga menyediakan kursus video pendidikan sebanyak lebih dari 150 video. Terdapat pasar untuk aplikasi yang dapat mengurangi biaya-biaya pinjaman, hal itu tidak perlu diragukan karena ada pasarnya, dengan banyaknya siswa yang mengambil pinjaman berkisar antara 20.000 sampai 60.000 dolar.

\section{KESIMPULAN}

Di era saat ini, desain kerangka Blockchain sangat diperlukan guna menyelesaikan permasalahan yang ada dalam dunia Pendidikan. Dalam penelitian ini menggunakan metode analisis dan pengumpulan data, diketahui bahwa teknologi Blockchain dapat diimplementasikan dalam dunia pendidikan karena sangat bermanfaat dan praktis. Dengan adanya teknologi Blockchain dapat menjadi solusi yang baik bagi permasalahan yang terjadi didunia pendidikan. Hal ini dapat dibuktikan dengan hadirnya desain kerangka, teknologi, bahkan layanan berbasis Blockchain yang sangat beragam serta berguna mengatasi permasalahan tersebut.

Desain kerangka Blockchain yang semakin berkembang dan banyak sangat berguna bagi individu ataupun universitas. Tidak hanya itu hadirnya teknologi dan layanan berbasis Blockchain yang sangat beragam memiliki manfaat tersendiri, sehingga kebermanfaatan Blockchain bagi permasalahan dunia Pendidikan sangat banyak. Salah satu yang tengah berkembang yaitu sertifikat digital berbasis teknologi Blockchain, yang mengamankan sertifikat dari pemalsuan dengan melakukan verifikasi dan autentifikasi.

Dalam penelitian dilanjutkan dengan hasil survei secara kuantitatif terhadap manfaat pengaplikasian Blockchain di dunia pendidikan Hal ini juga dapat diimplementasikan oleh dunia pendidikan secara global, sehingga semakin banyak kalangan yang merasakan manfaat besar dari Blockchain.

\section{UCAPAN TERIMAKASIH}

Penulis mengucapkan terimakasih kepada Universitas Raharja dan semua pihak yang telah memberi kesempatan kepada penulis untuk melakukan 
penulisan ini, dan juga telah memberi saran, dukungan serta bimbingannya sehingga penulisan ini dapat diselesaikan dengan baik.

\section{DAFTAR PUSTAKA}

Page | 244

[1] S. Nakamoto, "Bitcoin: A peer-to-peer electronic cash system," http://bitcoin. org/bitcoin. pdf," 2008.

[2] M. Conoscenti, A. Vetro, and J. C. De Martin, "Blockchain for the Internet of Things: A systematic literature review," in 2016 IEEE/ACS 13th International Conference of Computer Systems and Applications (AICCSA), 2016, pp. 1-6.

[3] C. Lukita, M. Hatta, E. P. Harahap, and U. Rahardja, "Crowd funding management platform based on block chain technology using smart contracts," Journal of Advanced Research in Dynamical and Control Systems, vol. 12, no. 2, 2020, doi: 10.5373/JARDCS/V12I2/S20201236.

[4] H. Yumna, M. M. Khan, M. Ikram, and S. Ilyas, "Use of Blockchain in Education: A Systematic Literature Review," in Asian Conference on Intelligent Information and Database Systems, 2019, pp. 191-202.

[5] M. B. Hoy, "An introduction to the blockchain and its implications for libraries and medicine," Medical reference services quarterly, vol. 36, no. 3, pp. 273279, 2017.

[6] I. Amsyar, E. Cristhopher, U. Rahardja, N. Lutfiani, and A. Rizky, "Application of Building Workers Services in Facing Industrial Revolution 4.0," Aptisi Transactions on Technopreneurship (ATT), vol. 3, no. 1, pp. 32-41, 2021.

[7] F. Agustin, Q. Aini, A. Khoirunisa, and E. A. Nabila, "Utilization of Blockchain Technology for Management E-Certificate Open Journal System," Aptisi Transactions on Management (ATM), vol. 4, no. 2, pp. 134-139, 2020

[8] Q. Aini, U. Rahardja, and A. Khoirunisa, "Blockchain Technology into Gamification on Education," IJCCS (Indonesian Journal of Computing and Cybernetics Systems), vol. 14, no. 2.

[9] M. Yusup, Q. Aini, D. Apriani, and P. Nursaputri, "PEMANFAATAN TEKNOLOGI BLOCKCHAIN PADA PROGRAM SERTIFIKASI DOSEN," in SENSITIf: Seminar Nasional Sistem Informasi dan Teknologi Informasi, 2019, pp. 365-371.

[10] P. A. Sunarya, U. Rahardja, L. Sunarya, and M. Hardini, "The Role Of Blockchain As A Security Support For Student Profiles In Technology Education Systems," InfoTekJar: Jurnal Nasional Informatika dan Teknologi Jaringan, vol. 4, no. 2, pp. 13-17, 2020.

[11] Q. Aini, U. Rahardja, N. P. L. Santoso, and A. Oktariyani, "Aplikasi Berbasis Blockchain dalam Dunia Pendidikan dengan Metode Systematics Review," CESS (Journal of Computer Engineering, System and Science), vol. 6, no. 1, pp. 58-66, 2021.

[12] G. Albeanu, "Blockchain technology and education," in The 12th International Conference on Virtual Learning ICVL, 2017, pp. 271-275.

[13] J. Rooksby and K. Dimitrov, "Trustless education? A blockchain system for university grades," 2017.

[14] F. Agustin, S. Syafnidawati, N. P. Lestari Santoso, and O. G. Amrikhasanah, "Blockchain-based Decentralized Distribution Management in E-Journals," Aptisi Transactions On Management, vol. 4, no. 2, pp. 107$113,2020$.
[15] U. Rahardja, E. P. Harahap, and D. D. Christianto, "Pengaruh Teknologi Blockchain Terhadap Tingkat Keaslian Ijazah," Technomedia J, vol. 4, no. 2, pp. 211-222, 2021.

[16] S. Sudaryono, Q. Aini, N. Lutfiani, F. Hanafi, and U. Rahardja, "Application of Blockchain Technology for iLearning Student Assessment," IJCCS (Indonesian Journal of Computing and Cybernetics Systems), vol. 14, no. 2.

[17] M. Alharby and A. van Moorsel, "Blocksim: a simulation framework for blockchain systems," ACM SIGMETRICS Performance Evaluation Review, vol. 46, no. 3, pp. 135-138, 2019.

[18] A. Adiyanto and R. Febrianto, "Authentication Of Transaction Process In E-marketplace Based On Blockchain technology," Aptisi Transactions On Technopreneurship (ATT), vol. 2, no. 1, pp. 68-74, 2020.

[19] N. P. Lestari, Y. Durachman, S. Watini, and S. Millah, "Manajemen Kontrol Akses Berbasis Blockchain untuk Pendidikan Online Terdesentralisasi," Technomedia Journal, vol. 6, no. $1,2021$.

[20] A. Grech and A. F. Camilleri, "Blockchain in education." Luxembourg: Publications Office of the European Union, 2017.

[21] G. Chen, B. Xu, M. Lu, and N.-S. Chen, "Exploring blockchain technology and its potential applications for education," Smart Learning Environments, vol. 5, no. 1 , p. 1,2018 .

[22] I.-C. Lin and T.-C. Liao, "A survey of blockchain security issues and challenges.," IJ Network Security, vol. 19, no. 5, pp. 653-659, 2017.

[23] E. P. Harahap, Q. Aini, and R. K. Anam, "PEMANFAATAN TEKNOLOGI BLOCKCHAIN PADA PLATFORM CROWDFUNDING," Technomedia Journal, vol. 4, no. 2, pp. 199-210, 2020.

[24] D. Mohanty, "Ethereum Use Cases," in Ethereum for Architects and Developers, Springer, 2018, pp. 203-243.

[25] "9 Blockchain Education Companies to Know | Built In.” https://builtin.com/blockchain/blockchaineducation (accessed Aug. 23, 2020).

[26] M. Turkanović, M. Hölbl, K. Košič, M. Heričko, and A. Kamišalić, "EduCTX: A blockchain-based higher education credit platform," IEEE access, vol. 6, pp. 5112-5127, 2018.

[27] A. Dudhat, N. P. L. Santoso, S. Santoso, and R. Setiawati, "Blockchain in Indonesia University: A Design Viewboard of Digital Technology Education," Aptisi Transactions on Technopreneurship (ATT), vol. 3, no. 1, pp. 68-80, 2021.

[28] P. Ocheja, B. Flanagan, and H. Ogata, "Connecting decentralized learning records: a blockchain based learning analytics platform," in Proceedings of the 
8th international conference on learning analytics and knowledge, 2018, pp. 265-269.

[29] T. Hepp, A. Schoenhals, C. Gondek, and B. Gipp, "OriginStamp: A blockchain-backed system for decentralized trusted timestamping," it-Information Technology, vol. 60, no. 5-6, pp. 273-281, 2018.

[30] T. Alam and M. Benaida, "Blockchain and Internet of Things in Higher Education," Universal Journal of Educational Research, vol. 8, no. 5, pp. 21642174,2020

[31] A. Williams and E. Dolan, "Application of Blockchain Technology in e-LoA Technopreneurship Journal," Aptisi Transactions On Technopreneurship (ATT), vol. 2, no. 1, pp. 98103, 2020.

[32] K. Kuvshinov, J. Mostovoy, and I. Nikiforov, "Disciplina: Blockchain for Education." 2018.

[33] R. Arenas and P. Fernandez, "CredenceLedger: a permissioned blockchain for verifiable academic credentials," in 2018 IEEE International Conference on Engineering, Technology and Innovation (ICE/ITMC), 2018, pp. 1-6.

[34] A. S. de P. Crespo and L. I. C. García, "Stampery Blockchain Timestamping Architecture (BTA)Version 6," arXiv preprint arXiv:1711.04709, 2017.

[35] Q. Aini, U. Rahardja, M. R. Tangkaw, N. P. L. Santoso, and A. Khoirunisa, "Embedding a Blockchain Technology Pattern Into the QR Code for an Authentication Certificate," Jurnal Online Informatika, vol. 5, no. 2, pp. 239-244, 2020.

[36] W. Gräther, S. Kolvenbach, R. Ruland, J. Schütte, C. Torres, and F. Wendland, "Blockchain for education: lifelong learning passport," 2018.
[37] U. Rahardja, A. N. Hidayanto, T. Hariguna, and Q. Aini, "Design Framework on Tertiary Education System in Indonesia Using Blockchain Technology," in 2019 7th International Conference on Cyber and IT Service Management (CITSM), 2019, vol. 7, pp. 1-4.

[38] S. Chan, "Blockchain Based Professional Networking and Recruiting Platform."

[39] U. Rahardja, Q. Aini, Y. I. Graha, and M. R. Tangkaw, "Gamification Framework Design of Management Education and Development in Industrial Revolution 4.0," in Journal of Physics: Conference Series, 2019, vol. 1364, no. 1, p. 12035.

[40] H. Elendner, S. Trimborn, B. Ong, and T. M. Lee, "The cross-section of crypto-currencies as financial assets: An overview," SFB 649 Discussion paper, 2016.

[41] D. J. Skiba, "The potential of Blockchain in education and health care," Nursing education perspectives, vol. 38, no. 4, pp. 220-221, 2017.

[42] A. Kiayias, A. Russell, B. David, and R. Oliynykov, "Ouroboros: A provably secure proof-of-stake blockchain protocol," in Annual International Cryptology Conference, 2017, pp. 357-388.

[43] L. Luu, V. Narayanan, C. Zheng, K. Baweja, S. Gilbert, and P. Saxena, "A secure sharding protocol for open blockchains," in Proceedings of the 2016 ACM SIGSAC Conference on Computer and Communications Security, 2016, pp. 17-30. 